\title{
Kenya public weather processed by the Global Yield Gap Atlas project
}

Hugo de Groot $^{1^{\star}}$, Ochieng Adimo ${ }^{2}$, Lieven Claessens ${ }^{3}$, Justin Van Wart ${ }^{4}$, Lenny G.J. van Bussel ${ }^{5}$, Patricio Grassini ${ }^{4}$, Joost Wolf ${ }^{5}$, Nicolas Guilpart ${ }^{4}$, Hendrik Boogaard ${ }^{1}$, Pepijn A.J. van Oort ${ }^{6}$, Haishun S. Yang ${ }^{4}$, Martin K. van Ittersum ${ }^{5}$, Kenneth G. Cassman ${ }^{4}$

${ }^{1}$ Wageningen Environmental Research (Alterra), Wageningen University and Research, Wageningen, The Netherlands,

${ }^{2}$ Jomo Kenyatta University of Agriculture and Technology, Nairobi, Kenya,

${ }^{3}$ International Crops Research Institute for the Semi-Arid Tropics, Nairobi, Kenya,

${ }^{4}$ Department of Agronomy and Horticulture, University of Nebraska-Lincoln, Lincoln, USA,

${ }^{5}$ Plant Production Systems, Wageningen University and Research, Wageningen, The Netherlands,

${ }^{6}$ Centre for Crop Systems Analysis, Wageningen University and Research, Wageningen, The

Netherlands.

*email: hugo.degroot@wur.nl

Abstract: The Global Yield Gap Atlas project (GYGA - http://yieldgap.org) has undertaken a yield gap assessment following the protocol recommended by van Ittersum et al. (2013). One part of the activities consists of collecting and processing weather data as an input for crop simulation models in sub-Saharan African countries including Kenya. This publication covers daily weather data for 12 locations in Kenya for the years 1998-2012. The project looked for good quality weather data in areas where crops are pre-dominantly grown. As locations with good public weather data are sparse in Africa, the project developed a method to generate bias corrected weather data from a combination of observed data and other external weather data. The bias corrected weather data consist of daily TRMM rain data and NASA POWER Tmax, Tmin, and Tdew data. These data are corrected based on calibrations with short-term ( $<10$ years) observed weather data.

Keywords: Kenya; weather data; crop simulation model; yield gap; crop yield; yield potential

1 ORIGINAL PURPOSE: The Global Yield Gap Atlas calculates yield gaps for the major food crops. The project uses a bottom-up approach to build on local practices and local knowledge on agronomic systems. In every investigated country the project seeks collaboration with agronomists and other local experts. Yield gaps $(\mathrm{Yg})$ are estimated by the difference between yield potential $(Y p)$ without limitations due to water or other abiotic and biotic stresses (the most relevant benchmark for irrigated systems), or water-limited yield potential ( $Y w)$ as the benchmark for rainfed systems, and actual crop yields (Ya). Eco-physiological crop simulation models are used to estimate $\mathrm{Yp}, \mathrm{Yw}$, and crop water availability to account for the influence of climate, soil-type and length of growing season as determined by climate, cultivar and dominant cropping systems at each location. In many parts of the world with sub-tropical and tropical climates, farmers grow two or three crops per year on the same field. In these regions farmers strive to optimize productivity of the entire cropping system rather than yield of a single crop to maximize returns to labour, land and time. Therefore, estimates of $Y p$, Yw, and WP for a given crop in those systems must account for actual length of growing season as constrained by the cropping system. The bottom-up approach of the GYGA protocol allows use of actual locationspecific data on current cropping systems, soil type, and long-term weather data from selected reference weather stations (RWS) so that results can be validated and improved upon as quality of such data improves and becomes available in major crop-producing regions worldwide. Where such data are of poor quality or not available, the GYGA utilizes the best existing data, or proxy data, with the goal of improving upon these data over time. As locations with good public weather data are sparse in Africa, the project developed a method to generate long term daily weather data from a combination of observed data and other external weather data (Van Wart et al. 2015). A detailed description of the method can be found at http://www.yieldgap.org/methods-weather-data. 
2 MEASURED DATA: For all locations short term observed weather data are available from the Kenya Meteorological Department. The time span and the number of days with actual measured data differ between locations. For all of them the coverage of measured data starts in 1998 and ends in 2007 or 2008, with gaps in between for some or for all variables.

3 BIAS CORRECTED DAILY WEATHER DATA: The observed short-term ( $<10$ years) weather data are used to calibrate data sources which do cover daily data for a long period: TRMM rainfall data and NASA POWER Tmax, Tmin, and Tdew data. The calibration step generates the data that get published here: bias corrected weather data generated from TRMM rainfall data and NASA POWER temperature data. The last step performed is some basic consistency checking. We checked rainfall $>=0$; Tmin $<$ Tmax. We checked annual rainfall sum $>300 \mathrm{~mm}$.

4 DESCRIPTION OF PROVIDED DATA: This publication covers daily weather data for 12 locations in Kenya. They all are located in areas where crops are grown.

Time coverage: Daily data for the years 1998- 2012.

Locations:The locations are listed in Table 1.

\begin{tabular}{llrr}
\hline Table 1. Locations & & & \\
\hline Name & Longitude & Latitude & Elevation (m) \\
\hline Dagoretti & 36.45 & -1.24 & 1798 \\
Embu & 37.58 & -0.49 & 1350 \\
Makindu & 37.82 & -2.29 & 1000 \\
Meru & 37.39 & 0.5 & 680 \\
Kakamega & 34.46 & 0.17 & 1530 \\
Kericho & 35.16 & -0.22 & 2093 \\
Nakuru & 36.60 & -0.16 & 1901 \\
Thika & 37.60 & -1.1 & 1631 \\
Eldoret & 35.30 & 0.48 & 2120 \\
Kisii & 34.79 & -0.68 & 1171 \\
Kisumu & 34.73 & -0.07 & 1146 \\
Kitale & 34.96 & 0.97 & 1850 \\
\hline
\end{tabular}

Variables: The variables provided are listed in Table 2.

\begin{tabular}{lll}
\hline Table 2. Variables & & \\
\hline Name & Description & Unit \\
\hline Solar radiation & sum of incoming short wave global & $\mathrm{MJ} / \mathrm{m} 2$ \\
& radiation & ${ }^{\circ} \mathrm{C}$ \\
MaxT & maximum temperature & ${ }^{\circ} \mathrm{C}$ \\
MinT & minimum temperature & $\% \%$ \\
Mean RelHum & mean relative humidity & $\mathrm{mm}$ \\
Precip & sum of precipitation & $\mathrm{m} / \mathrm{s}$ \\
Mean WndSpd & mean wind speed at 10 meter & ${ }^{\circ} \mathrm{C}$ \\
Mean Tdew & mean dew point temperature & \\
\hline
\end{tabular}

Format: 13 CSV files, packed in a zip file. 1 CSV file contains overall metadata, the other 12 CSV files contain location information and the daily weather data for the 12 locations. The size of the zip file is less than $1 \mathrm{Mb}$. The unzipped size of the CSV files is $3.5 \mathrm{Mb}$.

Link to the data: http://www.yieldgap.org/gygamaps/weatherdata/Kenya PublicWeatherDataCSV.zip

The data are also available in Excel format:

http://www.yieldgap.org/gygamaps/weatherdata/Kenya PublicWeatherData.xlsx 


\section{REFERENCES:}

Van Ittersum, M., Cassman K.G., Grassini, P., Wolf, J. Tittonell, P., Hochman, Z. 2013. Yield gap analysis with local to global relevance-A Review. Field Crops Research. 143, 4-17, http://dx.doi.org/10.1016/..fcr.2012.09.009

Van Wart, J., Grassini, P., Yang, H.S., Claessens, L., Jarvis, A., Cassman, K.G. 2015. Creating longterm weather data from the thin air for crop simulation modelling. Agricultural and Forest Meteorology. 208, 49-58, http://dx.doi.org/10.1016/i.agrformet.2015.02.020

Allen, R.G., Pereira, L.S., Raes, D., Smith, M. (1998) Crop evapotranspiration - guidelines for computing crop water requirements. FAO Irrigation and drainage paper 56. Food and Agriculture Organization, Rome, http://www.fao.org/docrep/x0490e/x0490e00.htm

GYGA Protocol for Weather Data, http://www.yieldgap.org/web/guest/methods-weather-data 